\title{
FABRICATION AND TESTING OF GYPSUM BLOCKS FOR SOIL MOISTURE DETERMINATION
}

\author{
${ }^{1}$ Ajayi A. S.*, ${ }^{2}$ Eleta P. O., ${ }^{3}$ Duweni E. C. and ${ }^{4}$ Ehiomogue P. \\ ${ }^{1}$ Department of Agricultural and Bio-Environmental Engineering Technology, Auchi Polytechnic Auchi \\ ${ }^{2}$ Department of Agricultural Technology, Auchi Polytechnic Auchi \\ ${ }^{3}$ Department of Civil Engineering, University of Ibadan, Oyo State Nigeria \\ ${ }^{4}$ Department of Agricultural Engineering, Michael Okpara University of Agriculture, Umudike, Abia State \\ Nigeria \\ *Corresponding author: ajayistan@gmail.com, +2348039714411
}

\begin{abstract}
Over the last decade, many new developments of soil moisture sensors have been evolved, especially those based on the frequency domain reflectometry (FDR) capacitance technique, due to the rapid developments in the microelectronics industry. This project work is aimed at field study of gypsum blocks for soil moisture determination. Three types of GBs were fabricated and used in this study. The dimension for GB as given by Michael (1978) was used as reference. The other two sizes were two-third $\left(\frac{2}{3}\right)$ and one and half $\left(1 \frac{1}{2}\right)$ of the Michael's size. The field evaluation of the three types of GB was carried out to measure soil moisture content. A field area of 3 by $4 \mathrm{~m}$ was prepared and three blocks each of the types fabricated were installed. The blocks were installed at $25 \mathrm{~cm}$ depth below the soil surface into holes made with augers. The block was calibrated using a log-log graph and exponential function to obtain the relationship between moisture content and resistance as $M c=21.884 \times R^{-0.05}$. The equation was used to evaluate the resistance based moisture content. The result shows that there is a variation in the moisture content using different sizes of blocks.
\end{abstract}

Keywords: fabrication, testing, soil moisture

DOI: $10.7176 / \mathrm{JNSR} / 9-3-09$

\section{INTRODUCTION}

In irrigation water management, water use represents a substantial opportunity for agriculture water savings. Automation of irrigation systems, based on Soil Moisture Sensors Systems (SMSS) has the potential to provide maximum water use efficiency by maintaining soil moisture at optimum levels. Fast and accurate monitoring of soil moisture plus the ability to do depth measurement is vital in this age of water scarcity. There is tremendous pressure and challenge to produce more out of less water, at the same time protecting and reducing risks to the environment. Some of the desirable attributes of the technique include being accurate, rapid, reliable, simple and cost-effective (Charlesworth, 2000). Over the last decade, many new developments of soil moisture sensors have been evolved, especially those based on the frequency domain reflectometry (FDR) capacitance technique, due to the rapid developments in the micro- electronics industry. This resulted in many relatively cheap and small sensors being manufactured, giving much more options to the traditional neutron scattering technique, which was the most commonly used method since its development in the 1950s (Gardner and Kirkham, 1952; Van Bavel et al., 1956; Gardner, 1986). While the new sensors claim to be accurate with minimal skill to operate, costeffective, and many have logging capability, their performance under different soil and cropping systems is only slowly being tested; few papers described comparisons of these methods with the traditional neutron-probe technique. However, it is well known that this category of sensors in general have a small sphere of influence and are very sensitive to small air gap around the tubes during installation, cracks and macrospores created by root activities, as well as positional changes in orientation within the tubes. Because of this, good sensor-tube-soil contact for reliable estimation of soil moisture is extremely critical (Evett and Steiner, 1995; Charlesworth, 2000).

Soil moisture is a major measurable parameter to be considered in making irrigation management decisions. To this regard, methods on how to provide adequate irrigation water have to be careful selected. Soil moisture measurement is one of the best and simplest ways to get feedback to help make improved water management decisions (Shock et al., 1998). Soil moisture monitoring optimizes irrigation by helping the irrigation manager keep soil water content within a target range. This practice reduces the potential for excess soil water and leaching of agrichemicals, but it requires selection of a suitable method for soil moisture estimation (MuñozCarpena et al., 2002; 2003).

The need to know how much water present in the soil arises frequently in many agro-ecological and agrohydrological investigations. As a result of the importance of knowing soil moisture status, so many methods and devices have evolved over the years to either directly measure or estimate soil moisture content. These methods and devices have been broadly classified by Pritchard (2005) into two: those that measure and express the soil 
moisture content quantitative (i.e. they indicate how much water present in the soil), and those that measure and express the soil moisture content qualitatively (i.e. they indicate how tight the water is held with the soil pores). Some of the quantitative methods and devices include the gravimetric method, neutron scatter method using the Neutron probe or Hydro-probe, dielectric constant method using devices like hand-push probe or Theta probe, Time Domain Reflectrometer (TDR) or Frequency Domain Reflectrometer (FDI). The qualitative methods and devices include the use of suction plate apparatus method, pressure plate and pressure membrane apparatus methods, use of tensiometers, porous blocks, and electrical resistance blocks commonly referred to a Gypsum Block (GB).

The GB has been around since the 1940s making it one of the oldest methods of soil moisture measurement (MEA, 1997). Ross (2007) described GB as electrical resistance device which uses gypsum $\left(\mathrm{CaSO}_{4}\right)$ as a porous material in which electrodes are embedded. The electrical resistance between the electrode changes with changes in moisture content. Thus, the measured electrical resistance can be calibrated to moisture content or tension in the soil (Ross, 2007). According to Majumdar (2004)), the electrical resistance of dry gypsum is nearly infinite, but when the gypsum is permeated with water, the electrical conductivity approximate that of an average textured soil at the same water content (Bouyoucos, 1965). The principle of operation then relies on hydraulic content between water in the porous block and soil water. Starting with a saturated soil and a saturated GB, the two systems are in equilibrium. As the soil dries, it matric potential becomes more negative, setting up a hydraulic gradient that results in water being removed from the gypsum block. With less water in the block, the electrical resistance increases. The opposite happens when the soil water content increase, the soil matric potential become less negative, water flows into the gypsum block and the electrical resistance decreases (Wood et al., 1998). This paper aims to fabricate and evaluate gypsum blocks for soil moisture measurement.

Two shapes of gypsum blocks are common: cylindrical and rectangular shapes with concentric or parallel electrodes (Godwin, 2000). The sizes of the rectangular shapes are about a match box (Campbell-Clause, 2005). Michael (1978) gave the dimension of the rectangular gypsum block as $5.5 \mathrm{~cm}$ long, $3.75 \mathrm{~cm}$ wide, and $2.0 \mathrm{~cm}$ thick, and acknowledged that the sensitivity of the block is affected by its size. However, the magnitude of the effect with respect to size of blocks was not reported. Michael (1978) also made mention of the use of a pair stainless wire mesh as electrodes in the gypsum block. The stainless wire mesh electrodes are to be placed $2.0 \mathrm{~cm}$ apart within the block and connected to electrical cables of desired length which the electrical resistance is measured. Another electrode material that has been suggested by Measurement Engineering Australia MEA (1997) is stainless steel rod like nails or motorbike spokes.

\section{MATERIALS AND METHODS \\ Fabrication of gypsum block}

Three types of GBs were fabricated and used in this study. Table 1 shows the description of the blocks as seen in plate 1. The dimension for GB as given by Michael (1978) was used as reference. The other two sizes were two-third $\left(\frac{2}{3}\right)$ and one and half $\left(1 \frac{1}{2}\right)$ of the Michael's size, respectively as shown in Table 1 . The electrode materials was stainless wire mesh.

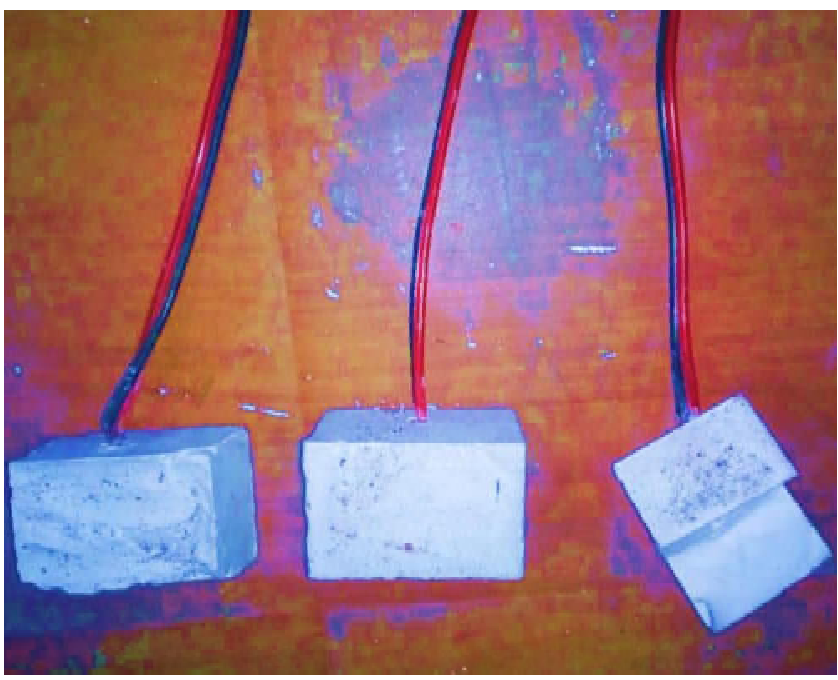

Plate 1: Fabricated gypsum blocks 
Table 1: Description of the gypsum blocks used in the study

\begin{tabular}{|c|c|c|}
\hline Type & $\begin{array}{c}\text { Block size (length } \mathrm{x} \\
\text { width } \mathrm{x} \text { thickness, } \mathrm{cm})\end{array}$ & Remark \\
\hline $\mathrm{I}$ & $5.5 \times 3.75 \times 2.0$ & Michael (1978) dimensions \\
\hline II & $3.7 \times 2.5 \times 1.3$ & Two-third of Michael's dimensions \\
\hline III & $8.25 \times 5.63 \times 3.0$ & One and half of Michael's dimensions \\
\hline
\end{tabular}

Rectangular molds were first prepared to the different sizes of blocks constructed using a soft plywood as shown in plate 2. Pair of electrodes (either wire mesh or stainless steel rod) was cut to size so that they can be completely buried within the blocks and covers $75 \%$ of the total length of the block. The pair of electrode for each block was placed $2 \mathrm{~cm}$ apart and connected to electrical cable cut to the desired length. Two parts of $\mathrm{CaSO}_{4}$ powder was properly mixed with one part of water forming a slurry or paste as shown in plate 3 , and was carefully poured into the molds making sure that the positions of the electrodes did not shift. The blocks were then allowed to dry under the sun for 48 hours, after which the molds were removed. The blocks were left in water for 24 hours, after which were allowed to dry in the open air at room temperature. While they were drying at room temperature, the changes in resistance were monitored twice a day for three days. This was done to test if the blocks were working, particularly to ascertain that the electrical cables were not disconnected from the electrode while casting the blocks.

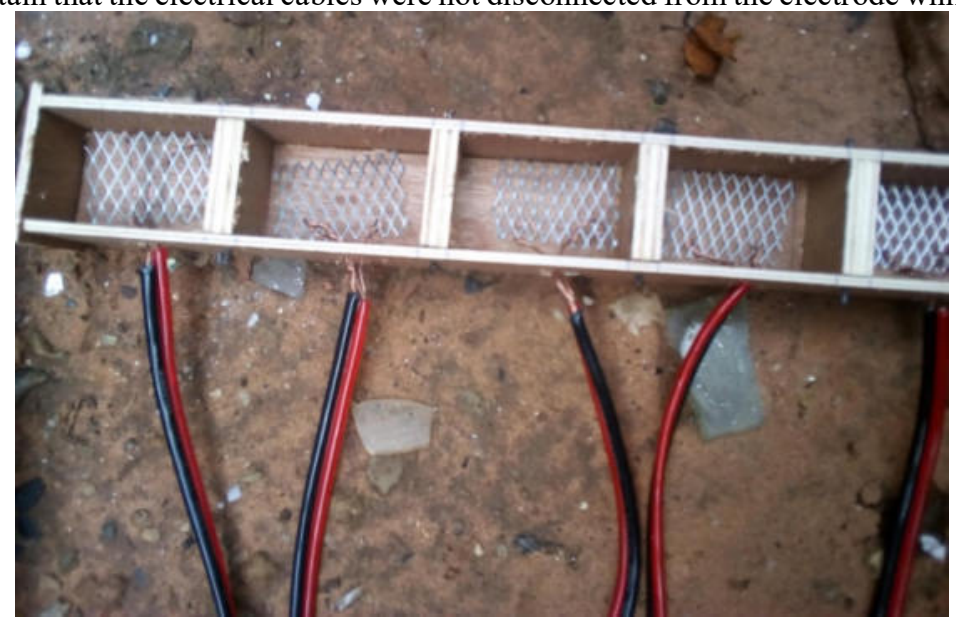

Plate 2: Mould formed for producing gypsum blocks

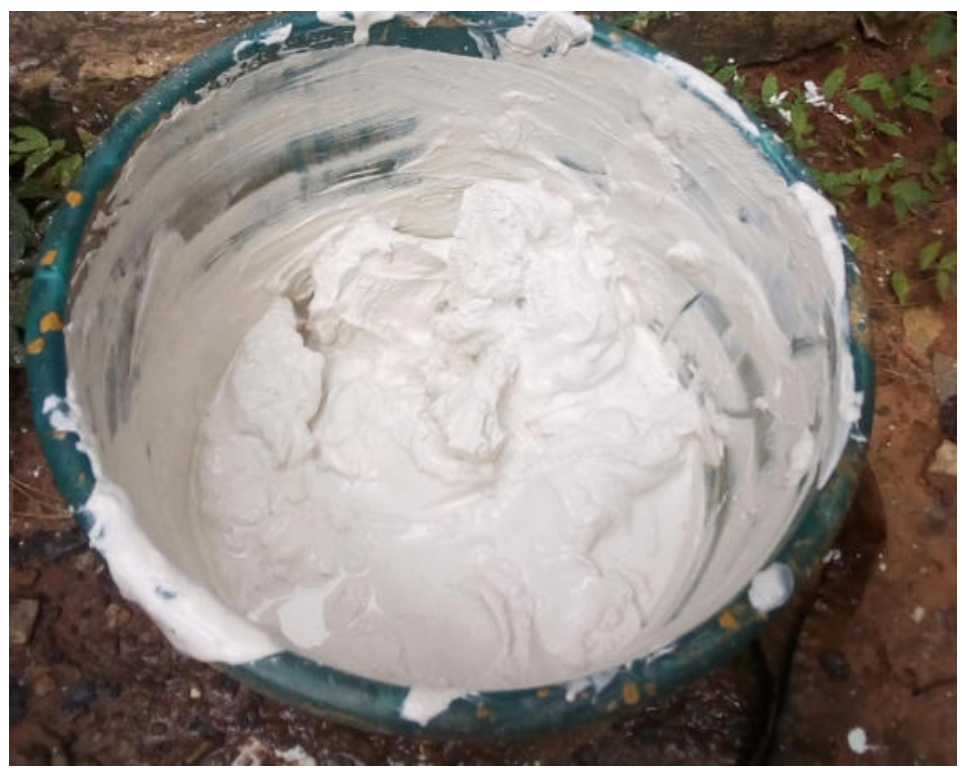

Plate 3: Gypsum mixed with water in slurry form 


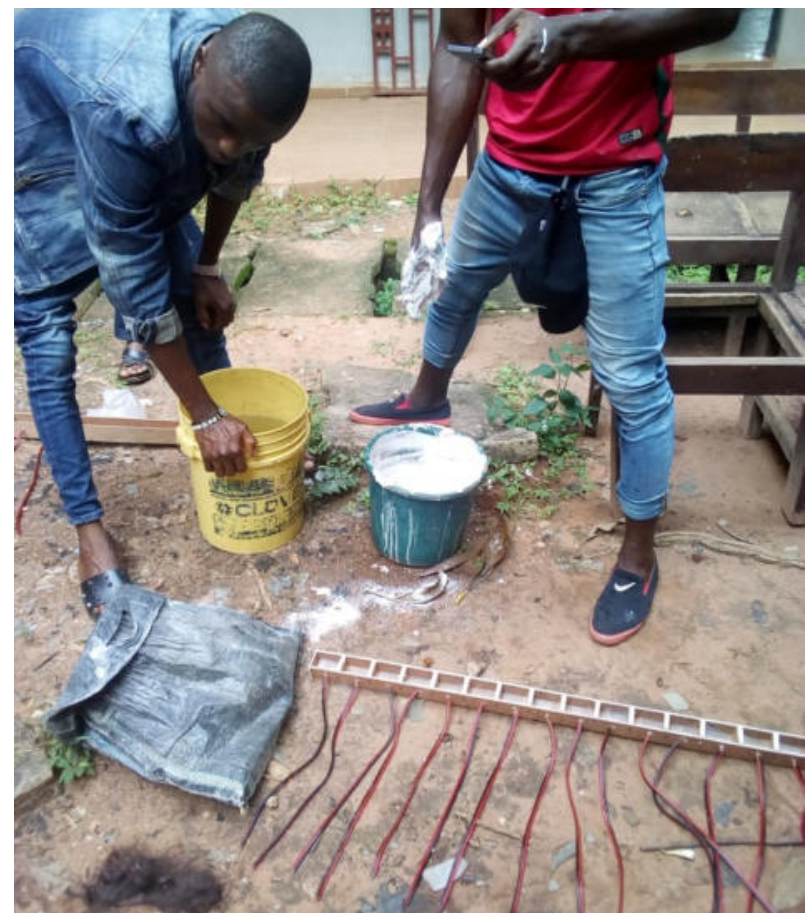

Plate 4: Pouring of mixture into the mould

Field evaluation of gypsum blocks

The field evaluation of the three types of GB was carried out to measure soil moisture content. A field area of 3 by $4 \mathrm{~m}$ was prepared and three blocks each of the types fabricated were installed. The blocks were installed at $25 \mathrm{~cm}$ depth below the soil surface into holes made with augers as shown in plate 5 and 6 . The installation procedures for the GB and the data collection which involved resistance measurement and determination of soil moisture status were similar to what was carried out in the laboratory experiment. However, the data collection for this experiment lasted for four weeks. The field evaluation was carried out during the rainy season so that variation in moisture content of the soil was as a result of rainfall.

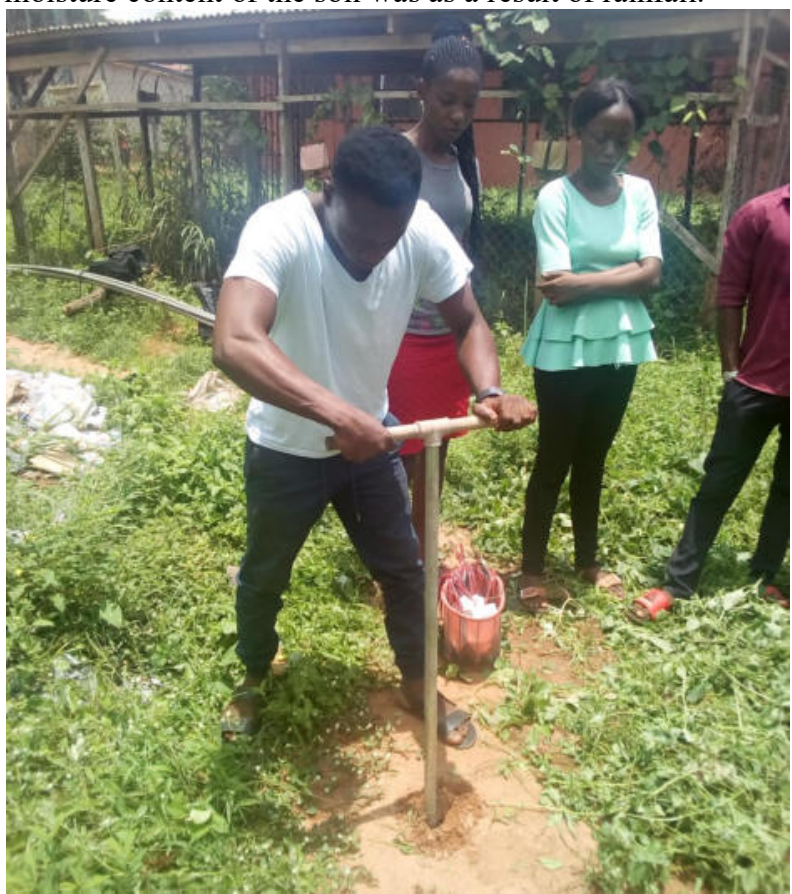

Plate 5: Using soil auger to create hole for gypsum block 


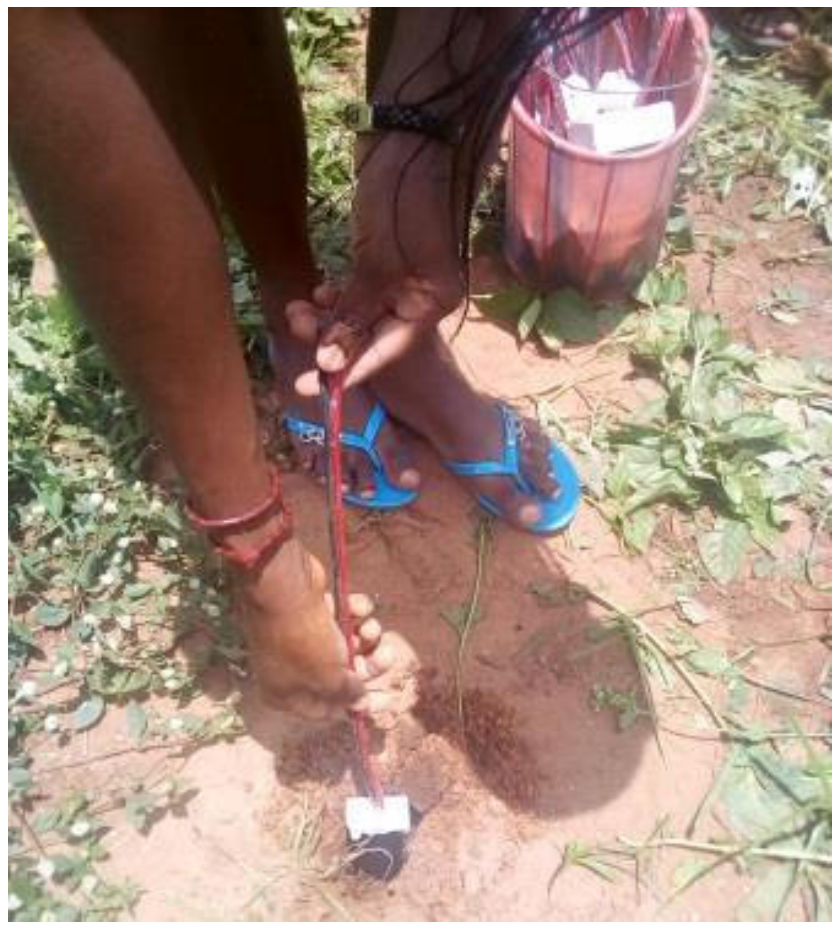

Plate 6: Gypsum block installation

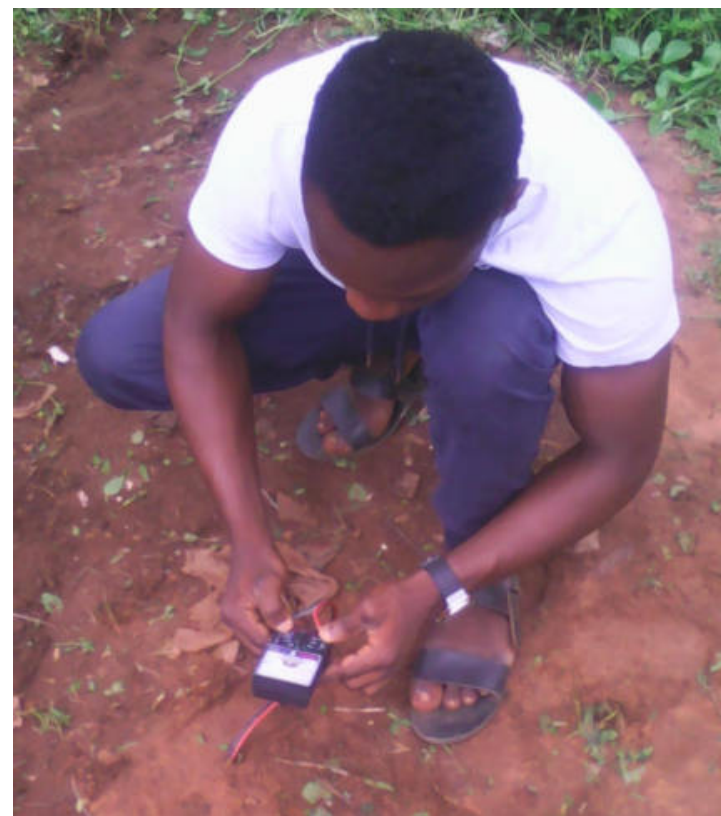

Plate 7: Soil moisture determination using Multimeter

\section{RESULTS AND DISCUSSION}

Results

The results obtained from the field test of the gypsum blocks are shown in Table 4.1, shows the soil moisture content and the electrical resistances data for the three GB types. The soil moisture content ranged from $13.5 \%$ to $23.1 \%$, while the electrical resistances ranged from $400 \mathrm{ohms}$ (recorded by the Type III block at the highest soil moisture content) to $18300 \mathrm{ohms}$. All the block types recording their least electrical resistance at the highest soil moisture content and their highest resistance values at the least soil moisture content. It could also be 
seen from the Table that the electrical resistances were also changing with changes in soil moisture content. This implied that all the block types were responsive and sensitivity to changes in moisture content.

Table 2: Soil moisture content and the electrical resistances of the six GB types

\begin{tabular}{|c|c|c|c|}
\hline MC dry weight \% & TYPE I & TYPE II & TYPE III \\
\hline 22.07 & 800 & 4600 & 400 \\
\hline 19.59 & 1000 & 8200 & 500 \\
\hline 20.88 & 1200 & 8300 & 600 \\
\hline 20.12 & 1400 & 10500 & 700 \\
\hline 21.45 & 1100 & 9900 & 900 \\
\hline 18.58 & 1600 & 10300 & 1000 \\
\hline 17.39 & 2300 & 13800 & 1400 \\
\hline 18.83 & 2100 & 14100 & 1200 \\
\hline 19.71 & 2000 & 12700 & 1200 \\
\hline 17.55 & 2300 & 14200 & 1300 \\
\hline 17.10 & 2600 & 14800 & 1400 \\
\hline 17.17 & 2700 & 15000 & 1400 \\
\hline 16.91 & 3000 & 15200 & 1600 \\
\hline 16.80 & 3100 & 15500 & 1600 \\
\hline 16.60 & 3300 & 15900 & 1700 \\
\hline 16.12 & 3500 & 16300 & 1800 \\
\hline 15.56 & 4400 & 17400 & 2000 \\
\hline 14.31 & 5400 & 18000 & 2200 \\
\hline 13.50 & 7100 & 18300 & 2500 \\
\hline $\begin{array}{ll}\text { Average } & 17.9\end{array}$ & 2678.9 & 13315.8 & 1336.8 \\
\hline
\end{tabular}

It may be observed from Table 3 the Type III block ( $1 \frac{1}{2}$ times the dimensions of the reference block size) recorded the least values of electrical resistance, while the Type II block $\left(\frac{2}{3}\right.$ times the dimensions of the reference block size with wire mesh electrodes) recorded the highest values of electrical resistances.

The implication of these results is that block size do affect the response of the gypsum block. Blocks of smaller sizes gives higher values of electrical resistance while blocks of larger sizes tend to give lower electrical resistance values for the same soil moisture content. One reason while the smaller block size may show higher resistance values may be because it holds less water as the moisture content of the soil decreases compare to the blocks of larger size.

\section{Calibration of the blocks}

Figures 4.1 show the relationship between the electrical resistance and the soil moisture content in percent dry weight basis $(\% \mathrm{db})$ for the soil studied. The equations describing the relationships were obtained as:

$$
M c=21.884 \times R^{-0.05}
$$

Where: Mc is Moisture content (\% dry weight basis)

$$
\mathrm{R}=\text { Electrical resistance (ohms) }
$$




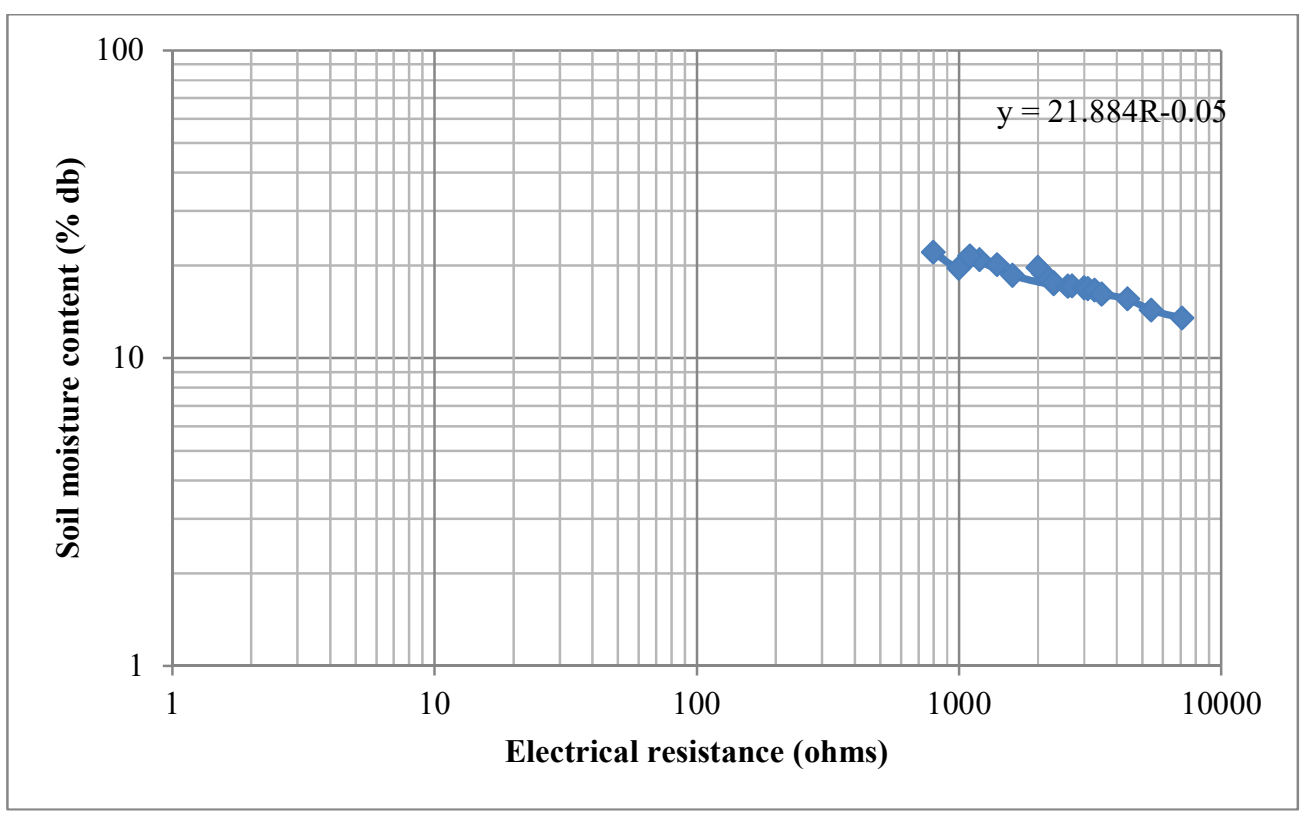

Figure 4.1: Gypsum block calibration curve for the field

The exponential equation obtained from the Log-Log graph was used to calculate the resistance based moisture content of the field as shown in table 4.2 .

Table 3: Resistance based moisture content of the field with their respective $\mathrm{R}^{2}$ values

\begin{tabular}{cccc}
\hline $\begin{array}{c}\text { Observed Moisture } \\
\text { content (\%) }\end{array}$ & $\begin{array}{c}\text { Resistance based MC } \\
\text { for Type I GB block }\end{array}$ & $\begin{array}{c}\text { Resistance based MC } \\
\text { for Type II GB block }\end{array}$ & $\begin{array}{r}\text { Resistance based MC } \\
\text { for Type III GB block }\end{array}$ \\
\hline 22.07 & 15.67 & 14.35 & 16.22 \\
19.59 & 15.49 & 13.95 & 16.04 \\
20.88 & 15.35 & 13.94 & 15.89 \\
20.12 & 15.23 & 13.77 & 15.77 \\
21.45 & 15.42 & 13.81 & 15.57 \\
18.58 & 15.13 & 13.79 & 15.49 \\
17.39 & 14.86 & 13.59 & 15.23 \\
18.83 & 14.93 & 13.57 & 15.35 \\
19.71 & 14.96 & 13.64 & 15.35 \\
17.55 & 14.86 & 13.57 & 15.29 \\
17.1 & 14.77 & 13.54 & 15.23 \\
17.17 & 14.74 & 13.53 & 15.23 \\
16.91 & 14.66 & 13.52 & 15.13 \\
16.8 & 14.64 & 13.51 & 15.13 \\
16.6 & 14.59 & 13.49 & 15.09 \\
16.12 & 14.55 & 13.47 & 15.04 \\
15.56 & 14.39 & 13.43 & 14.96 \\
14.31 & 14.24 & 13.41 & 14.89 \\
13.5 & 14.05 & 13.40 & $\mathbf{0 . 8 2}$ \\
\hline $\mathbf{R}^{2}$ & $\mathbf{0 . 9 3}$ & $\mathbf{0 . 7 5}$ & \\
\hline & & & 14.80 \\
\hline
\end{tabular}


The table shows that Type I gypsum block measured moisture content more accurately than others, $\mathrm{R}^{2}$ of 0.93 was obtained which is closer to unity (1) for perfect fit between observed and resistance based moisture content.

\section{CONCLUSIONS}

Three sizes of rectangular gypsum blocks were fabricated and tested to measure soil moisture content for Agricultural Engineering Demonstration Farm. The electrical resistance of one of the three blocks types with dimensions $5.5 \mathrm{~cm}$ long, $3.75 \mathrm{~cm}$ wide, and $2.0 \mathrm{~cm}$ thick and stainless wire mesh as electrode material (being the specifications given by Michael, 1978), was used as reference for the other two blocks. The electrical resistance of the gypsum blocks was found to be affected by block size.

\section{REFERENCES}

Bouyoucos, G. J., 1965. Plaster of Paris block electrical measuring unit for making a continuous measurement of soil moisture under field conditions. In A Wexler (ed.), Humility and Moisture: measurement and control in science and industry (Vol. 4, pp $105-111)$. New York: Reinhold.

Campbell-Clause, J.M. 2005 (Review). Using gypsum blocks to measure soil moisture in Vineyards. Department of Agriculture and Food Western Australia. Farm note no.3/98

Charlesworth, P. (2000). Soil water monitoring. National Program for Irrigation Research and Development.CSIRO Land and Water.101 p.

Charlesworth, P. (2005), Soil Water Monitoring, Irrigation Insights No. 1, Second Edition.

Evett, S.R., and Steiner J.L . (1995). Precision of neutron scattering and capacitance type soil water content gauges from field calibration. Soil Sc. Soc. of Am. J. 59:961-968.

Gardner, W. and D. Kirkham.(1952). Determination of soil moisture by neutron scattering. Soil Sci. 73:391-401.

Gardner, W.H.,(1986). Water content. In A. Klute (ed.). Methods of Soil Analysis, Part 1. $2^{\text {nd }}$. Am. Soc. Agron., Soil Sci. Soc. Am., Madison, WI, USA.

Godwin, I. 2000. Gypsum blocks for measuring the dryness of soil. State of Victoria Department of Primary Industries. Agriculture notes AG0294: 1-3

Majumdar, D.K., 2004. Irrigation Water Management: Principles and Practice. Prentice Hall of India Private Limited. M-97 Connaught Circus, New Delhi, India, pp 174-212

Michael, A. M., 1978. Irrigation Theory and Practice. Viska Publishing House PVTLTO New Delhi.

Ross, B.B. 2007. Peanut Irrigation, Peanut Production Guide: pp 64-67

Shock, C.C., Barnum, J.M. and Seddigh M.(1998). Calibration of Watermark Soil Moisture Sensors for irrigation management. p. 139-146 in Proceedings of the International Irrigation Show, Irrigation Association, San Diego, CA.

Van Bavel, C.H.M., Underwood N. and Swanson, R.W. (1956). Soil moisture measurement by neutron moderation. Soil Sci. 82:29-41.

Wood, M., Hector, M., and Turral, H., 1998. Real-time monitoring and control of on-farm surface Irrigation Systems. Final Report. Department of Civil and Environmental Engineering University of Melbourne. 84pp. 